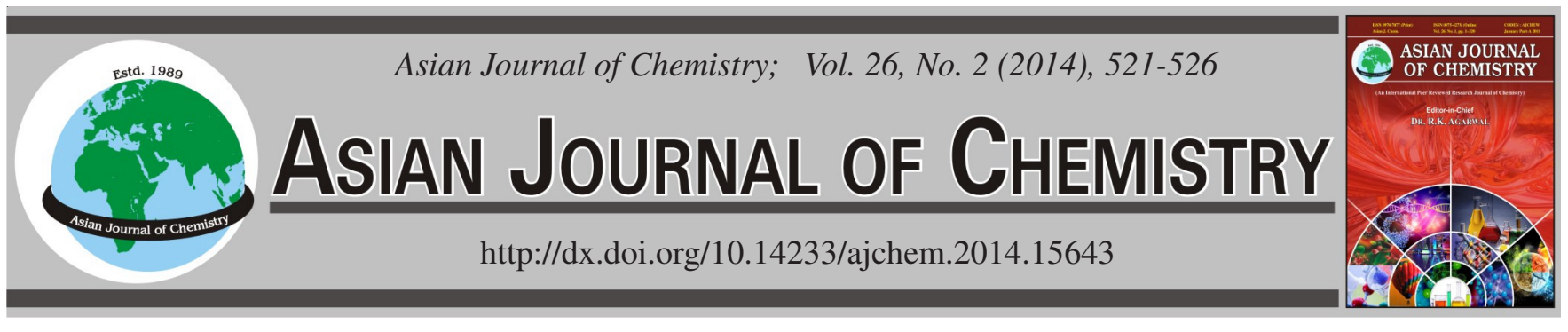

\title{
Study of Interaction Between Sodium Fluorescein and Human Serum Albumin by Multi-Spectroscopic Method
}

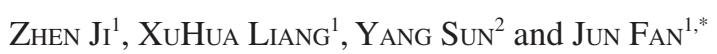

${ }^{1}$ School of Chemical Engineering, Northwest University, No.229 Taibai North Road, Xi'an 710069, Shaanxi Province, P.R. China ${ }^{2}$ Department of Chemistry \& Chemical Engineering, Xi'an University of Arts and Science, Xi'an 710069, Shaanxi Province, P.R. China

*Corresponding author: Tel: +86 29 88305252; E-mail: fanjun@nwu.edu.cn; fzghc@126.com

The efficacy of sodium fluorescein (SF) binding to human serum albumin (HSA) is critical for the clinical application of sodium fluorescein in confocal laser endomicroscopy (CLE). The interactions between sodium fluorescein and human serum albumin under simulative physiological conditions were investigated by the methods of fluorescence spectroscopy, UV-visible absorption and circular dichroism spectroscopy. Fluorescence data revealed that the fluorescence quenching of human serum albumin by sodium fluorescein was resulted of the formation of the SF-HSA complex. According to the modified Stern-Volmer equation, the binding constants $\left(\mathrm{K}_{\mathrm{b}}\right)$ between sodium fluorescein and human serum albumin at four different temperatures were obtained to be $1.75,1.60,1.46,1.33 \times 10^{5} \mathrm{M}^{-1}$, respectively. The thermodynamic parameters, enthalpy change $(\Delta \mathrm{H})$ and entropy change $(\Delta \mathrm{S})$ for the reaction were calculated to be $-17.55 \mathrm{~kJ} \mathrm{~mol}^{-1}$ and $41.48 \mathrm{~J} \mathrm{~mol}^{-1} \mathrm{~K}^{-1}$ according to van't Hoff equation, indicating that electrostatic interactions were the dominant intermolecular force in stabilizing the complex. The effect of sodium fluorescein on the conformation of human serum albumin was also analyzed by synchronous fluorescence, three-dimensional fluorescence and circular dichroism spectra. The results showed that the presence of sodium fluorescein decreased the $\alpha$-helical content of human serum albumin (from 46.15-38.79\%) and induced the slight unfolding of the polypeptides of protein, which confirmed some micro-environmental and conformational changes of human serum albumin molecules.
\end{abstract}

Keywords: Sodium fluorescein, Human serum albumin, Fluorescence spectroscopy, Circular dichroism.

\section{INTRODUCTION}

Serum albumins, as a principal extracellular protein constituent of blood plasma, play a dominant role in the transport and disposition of a variety of endogenous and exogenous substances such as dyes and drugs. The absorption, metabolism properties as well as the bioactivity and toxicity of dyes and drugs can be significantly affected as a result of their binding to serum albumins ${ }^{1}$. Moreover, the interactions with low weight dyes and drugs have an important effect on the secondary and tertiary structure of albumins ${ }^{2}$. Human serum albumin (HSA) is a globular protein composed of 585 amino acid residues in three homologous $\alpha$-helical domains (I, II, III). Each domain contains 10 helices and is divided into six antiparallel helices and four subdomains $(\mathrm{A} \text { and } \mathrm{B})^{3}$. Two hydrophobic pockets are present in sub-domains IIA and IIIA, which accommodate the bioactive molecules to bind reversibly ${ }^{4}$.

Confocal laser endomicroscopy (CLE) has been recently proposed as a new technique that allows in vivo histology at subcellular resolution during ongoing endoscopy and permits subsurface imaging of normal and neoplastic human mucosa ${ }^{5}$.
The most commonly used contrast agents are acriflavine hydrochloride and sodium fluorescein ${ }^{6}$. Sodium fluorescein (Fig. 1) is a relatively low-molecular-weight, highly watersoluble compound with nonspecific staining properties ${ }^{7}$. Within seconds of intravenous administration, sodium fluorescein binds extensively to serum albumin in the blood, establishing a stable distribution throughout the entire mucosa and providing strong contrast, which is helpful for accessing to high resolution cross-section images of colonic pit patterns, surface epithelial cells, connective tissue matrix of the lamina propria, blood vessels and red blood cells ${ }^{8-10}$. Consequently, studying structural dynamics between dyes and serum albumins is crucial not only for understanding the binding mechanism and metabolic pathway of dye in vitro, but also for leading to real-time early diagnosis of neoplastic changes and modifing the clinical management of cancer patients ${ }^{11}$.

It has recently been proved that serum albumin plays a decisive role in the transport and disposition of some bioactive dyes like Sudan ${ }^{12}$, bromopyrogallol red ${ }^{13}$, C.I. Direct Yellow $9^{14}$, malachite green ${ }^{15}$ and acridine orange ${ }^{16}$. Early work has been carried out on the binding of sodium fluorescein to bovine 
<smiles>NC(=O)c1ccccc1-c1c2ccc(=O)cc-2oc2cc(O[N+](=O)[O-])ccc12</smiles>

Fig. 1. Structure of sodium fluorescein (SF)

serum albumin $(\mathrm{BSA})^{17}$, but no study has focused on the physicochemical and conformational studies of interaction between sodium fluorescein and human serum albumin during binding procedure.

In this work, we have performed for the first time extended studies on the binding properties (including binding mechanism, binding constant and the number of binding sites) of sodium fluorescein to human serum albumin at four temperatures under physiological conditions utilizing fluorescence method. Thermodynamic parameters have been calculated according to the van't Hoff equation to determine the types of interactions involved. Great attempts were made to investigate the effect of sodium fluorescein on the micro-environmental and conformational changes of human serum albumin employing a mix of synchronous fluorescence, three-dimensional fluorescence, circular dichroism spectroscopy experiments. We hope this work can not only provide useful information for appropriately understanding the action of active contrast agent in dyes, but also illustrate its binding mechanisms at a molecular level.

\section{EXPERIMENTAL}

Human serum albumin and sodium fluorescein (SF) were purchased from Sigma Chemical Company. Human serum albumin stock solutions $(5.0 \mu \mathrm{M})$ were prepared by dissolving $6.6 \mathrm{mg}$ in $20 \mathrm{~mL} \mathrm{pH} 7.4$ buffer solutions and kept in dark at $277 \mathrm{~K}$. The stock solution $(50.0 \mu \mathrm{M})$ of sodium fluorescein was prepared by dissolving $0.37 \mathrm{mg}$ in $20 \mathrm{~mL}$ water. The buffer ( $\mathrm{pH}$ 7.4) consists of tris $\left(0.2 \mathrm{M}^{-1}\right)$ and $\mathrm{HCl}\left(0.1 \mathrm{M}^{-1}\right)$. All reagents were of analytical reagent grade and distilled water was used throughout the experiment.

The fluorescence measurements were carried out on an F-7000 fluorescence spectrometer (Hitachi, Japan) equipped with a $150 \mathrm{~W}$ Xenon lamp and a slit width of $5 \mathrm{~nm}$. UV-visible absorption spectra were recorded at room temperature with a UV-2501PC spectrophotometer (Shimadzu, Japan). A $1.0 \mathrm{~cm}$ quartz cell was used for measurements. Circular dichroism (CD) measurements were performed on a J-810 spectropolarimeter (Jasco, Tokyo, Japan) with a quartz cell having path lengths of $0.1 \mathrm{~cm}$. All $\mathrm{pH}$ measurements were made with a PHS-3CF acidity meter (Shanghai, Leici Instrument Co., Ltd., China).

\section{Procedure}

Fluorescence measurements: $2 \mathrm{~mL}$ solution containing $5 \mu \mathrm{M}$ human serum albumin was titrated manually by successive addition of sodium fluorescein solution (to give a final concentration ranging from 0 to $2 \mu \mathrm{M}$ with trace syringes and the fluorescence intensity was measured (excitation at $280 \mathrm{~nm}$ and emission at $340 \mathrm{~nm}$ ) at four different temperatures (298, 302,306 and $310 \mathrm{~K}$ ). The temperature of sample was kept by recycled water throughout the experiment.

Synchronous fluorescence spectra of human serum albumin with various concentrations of sodium fluorescein were obtained from 200 to $400 \mathrm{~nm}(\Delta \lambda=15 \mathrm{~nm}$ and $\Delta \lambda=60 \mathrm{~nm})$ with the excitation and emission slit widths of $5 / 5 \mathrm{~nm}$, respectively.

Three-dimensional fluorescence spectra were collected with setting excitation wavelength from 200 to $320 \mathrm{~nm}$, emission wavelength from 200 to $400 \mathrm{~nm}$ with increment $2.5 \mathrm{~nm}$.

UV Absorbance measurements: The UV spectra were obtained by scanning the solution on the spectrophotometer with the wavelength range of 200 to $400 \mathrm{~nm}$. The operations were carried out at room temperature.

Circular dichroism (CD) measurements: CD spectra of human serum albumin $(5.0 \mu \mathrm{M})$ in absence and presence of sodium fluorescein (the molar ratio of human serum albumin to sodium fluorescein was varied as 1:3, 1:5 and 1:10, respectively) were made in the range of 200-260 nm and the results were expressed in terms of mean residue ellipticity (MRE). Buffer solution as reference was subtracted from the sample spectra. The operations were carried out at room temperature.

\section{RESULTS AND DISCUSSION}

Fluorescence quenching mechanism and binding constant: Fluorescence quenching is the decrease of the quantum yield of fluorescence from a fluorophore induced by a variety of molecular interactions, such as excited-state reactions, energy transfer, ground-state complex formation and collisional quenching ${ }^{18}$. The different mechanisms of quenching are usually classified as dynamic quenching and static quenching or static and dynamic quenching participates simultaneously. Dynamic quenching depends upon diffusion. Since higher temperature results in larger diffusion coefficient, the bimolecular quenching constant is expected to be higher with increasing temperature. In contrast, increased temperature is likely to result in decreased stability of the complex and thus lower value of the static quenching constant ${ }^{19}$. In this paper, the fluorescence quenching spectra of human serum albumin were measured in the presence of different concentrations of sodium fluorescein at four different temperatures (the temperatures used were 298, 302, 306 and $310 \mathrm{~K}$ ) to elucidate the quenching mechanism.

It was found that addition of sodium fluorescein resulted in a concentration dependent quenching of the intrinsic fluorescence of human serum albumin along with a slight red shift $(3 \mathrm{~nm})$ in the emission maximum (Fig. 2). These phenomena indicated that sodium fluorescein could interact with human serum albumin and quench its intrinsic fluorescence and the microenvironment of tryptophan was more hydrophilic.

The fluorescence quenching is usually described by the Stern-Volmer equation:

$$
\frac{\mathrm{F}_{0}}{\mathrm{~F}}=1+\mathrm{K}_{\mathrm{SV}}[\mathrm{Q}]=1+\mathrm{K}_{\mathrm{q}} \tau_{0}[\mathrm{Q}]
$$

where $\mathrm{F}_{0}$ and $\mathrm{F}$ denote the steady-state fluorescence intensities in the absence and presence of quencher (sodium fluorescein), respectively, $\mathrm{K}_{\mathrm{Sv}}$ is the Stern-Volmer quenching constant and [Q] is the quencher concentration, $K_{q}$ is the biomolecule quenching rate constant of the biological macromolecule and 


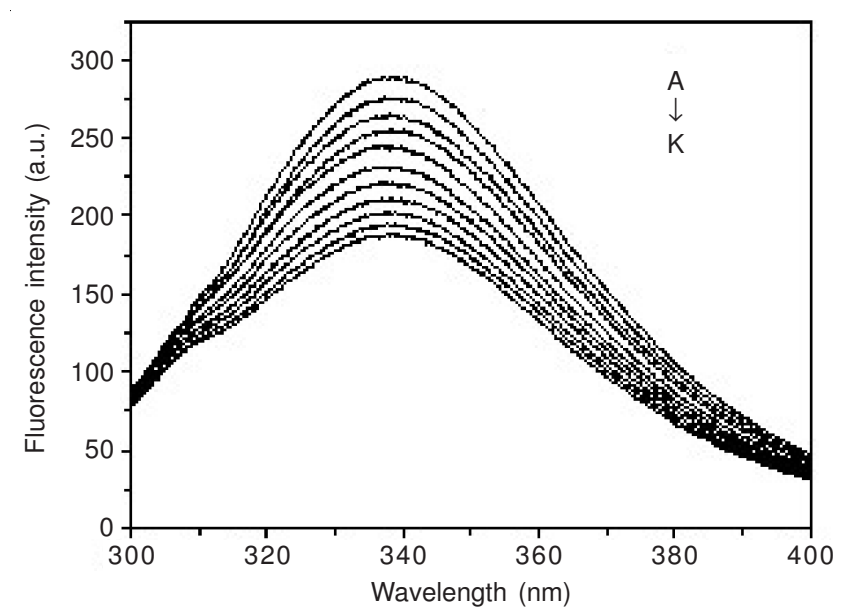

Fig. 2. Fluorescence spectra of the SF-HSA system $\left(\mathrm{T}=298 \mathrm{~K}, \boldsymbol{\lambda}_{\mathrm{ex}}=280\right.$ $\mathrm{nm}) . \mathrm{c}(\mathrm{HSA})=5.0 \mu \mathrm{M} ; \mathrm{c}(\mathrm{SF}) /(\mu \mathrm{M}), \mathrm{A}-\mathrm{K}: 0,0.2,0.4,0.6,0.8,1.0$, $1.2,1.4,1.6,1.8,2.0$

$\mathrm{K}_{\mathrm{q}}=\mathrm{K}_{\mathrm{SV}} / \tau_{0} . \tau_{0}$ is the average lifetime of the molecule without any quencher and the fluorescence lifetime of the biopolymer is $2.0 \times 10^{-8} \mathrm{~s}^{20}$. Hence, eqn. 1 was applied to determine $\mathrm{K}_{\mathrm{SV}}$ by linear regression of a plot of $\mathrm{F}_{0} / \mathrm{F}$ against [Q].

Fig. 3 showed the Stern-Volmer ploted of $\mathrm{F}_{0} / \mathrm{F}$ versus [Q] at four temperatures, the calculated $\mathrm{K}_{\mathrm{Sv}}$ values were presented in Table-1. It indicated that the calculated $\mathrm{K}_{\mathrm{SV}}$ decreased with the rising temperature. The values of $\mathrm{K}_{\mathrm{q}}$ were much larger than the maximum scattering collision quenching constant $\left(2 \times 10^{10} \mathrm{M}^{-1} \mathrm{~s}^{-1}\right)^{21}$, which indicated that the fluorescence quenching of human serum albumin was caused by a specific interaction between sodium fluorescein and human serum albumin. The quenching mechanism was mainly arisen from the predominant of complexes formation, while dynamic collision could be negligible in the concentration studied ${ }^{22}$.

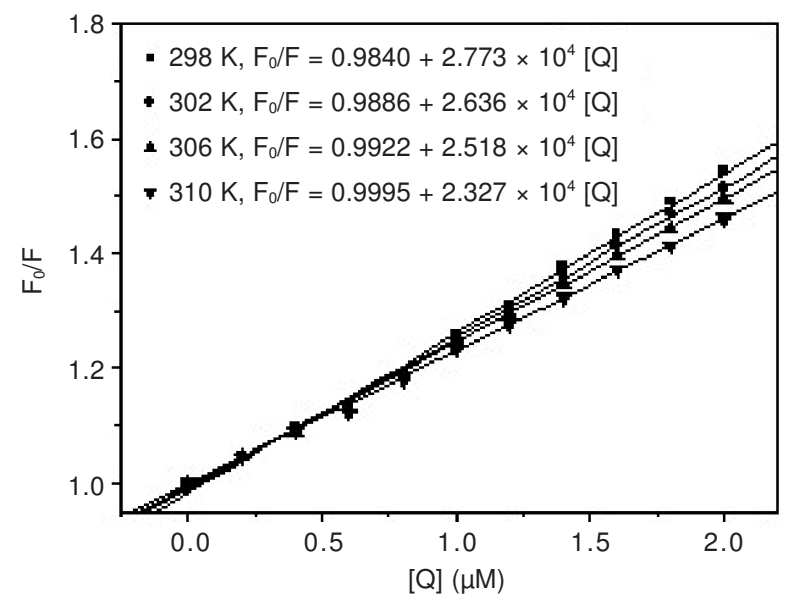

Fig. 3. Stern-Volmer plots for the SF-HSA system at four different temperatures, $\mathrm{pH} 7.4$
According to Sharma et al., dynamic quenching affects the excited states of molecules rather than the absorption spectra of fluorescent substance ${ }^{23}$. The UV-visible absorption spectra of human serum albumin were also recorded in the presence of different concentrations of sodium fluorescein at room temperature (Fig. 4) to confirm the probable quenching mechanism. It is noted from Fig. 4 that the absorbance of human serum albumin was increased with the addition of sodium fluorescein along with a blue shift. This result confirmed that the quenching was mainly a static quenching process and at least a SF-HSA complex with certain new structure was formed.

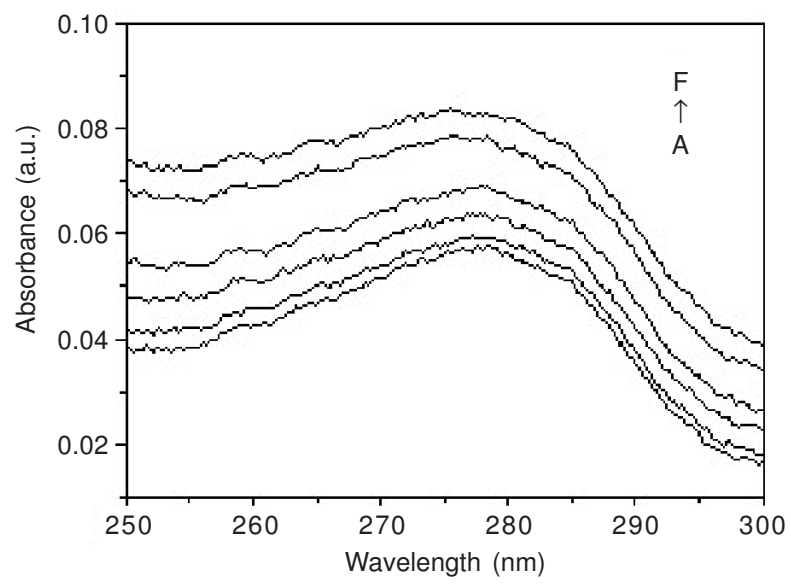

Fig. 4. UV-visible absorption spectra of human serum albumin in the presence of various concentrations of sodium fluorescein at room temperature. $\mathrm{c}(\mathrm{HSA})=5.0 \mu \mathrm{M} ; \mathrm{c}(\mathrm{SF}) /(\mu \mathrm{M}), \mathrm{A}-\mathrm{F}: 0,0.2,0.4,0.6$, $0.8,1.0$

Identification of binding site of sodium fluorescein on human serum albumin: When small molecules bind independently to a set of equivalent sites on a macromolecule, the binding constant $\left(\mathrm{K}_{\mathrm{b}}\right)$ and numbers of binding sites $(\mathrm{n})$ can be determined by the following equation ${ }^{24}$ :

$$
\log \left[\frac{\left(F_{0}-F\right)}{F}\right]=\log \mathrm{K}_{\mathrm{b}}+\mathrm{n} \log [\mathrm{Q}]
$$

where $\mathrm{K}_{\mathrm{b}}$ is the binding constant for SF-HSA interaction, $\mathrm{n}$ is the number of binding sites per human serum albumin and $\mathrm{F}_{0}$, $F$, [Q] have the same meanings as in eqn. 1. The values of $K_{b}$ and $\mathrm{n}$ could be measured from the intercept and slope by plotting $\log \left[\left(\mathrm{F}_{0}-\mathrm{F}\right) / \mathrm{F}\right]$ against $\log [\mathrm{Q}]\left(\right.$ intercept $=\log \mathrm{K}_{\mathrm{b}}$, slope $=\mathrm{n}$ ) and the plot was shown in Fig. 5. The corresponding values of $\mathrm{n}$ are presented in Table- 1 . The value of $\mathrm{n}$ approximately equaled to 1 indicating that there is one class of binding sites to sodium fluorescein in human serum albumin. Hence, the sodium fluorescein most likely bound to the hydrophobic pocket located in subdomain IIA; that is to say, Trp 214 is near or within the binding site ${ }^{18}$. The $K_{b}$ values show that the

\begin{tabular}{ccccccc}
\multicolumn{7}{c}{ TABLE-1 } \\
\multicolumn{7}{c}{ BINDING AND THERMODYNAMIC PARAMETERS FOR THE INTERACTION OF SODIUM } \\
\\
FLUORESCEIN WITH HUMAN SERUM ALBUMIN AT FOUR DIFFERENT TEMPERATURES
\end{tabular}




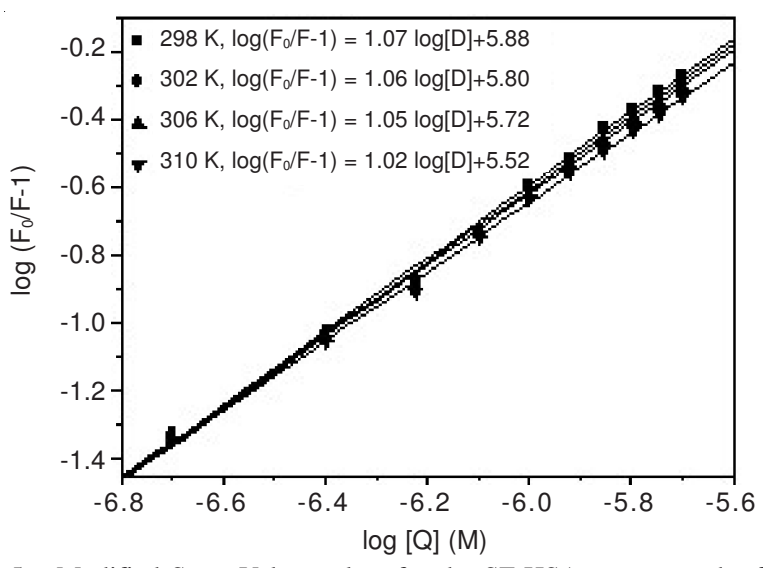

Fig. 5. Modified Stern-Volmer plots for the SF-HSA system at the four different temperatures

binding between sodium fluorescein and human serum albumin was moderate, which indicated that a reversible SF-HSA complex came into being and that it could circulate through the system and serve as a depot of sodium fluorescein ${ }^{25}$.

Type of interaction force between sodium fluorescein and human serum albumin: The acting forces between a small organic molecule and biomolecule may include hydrophobic force, electrostatic interactions, van der Waals interactions, hydrogen bonds. It is assumed that the interaction enthalpy change $(\Delta \mathrm{H})$ does not vary significantly over the temperature range studied and then the thermodynamic parameters can be estimated from the van't Hoff equation:

$$
\ln \mathrm{K}=-\frac{\Delta \mathrm{H}}{\mathrm{RT}}+\frac{\Delta \mathrm{S}}{\mathrm{R}}
$$

The free energy change $(\Delta \mathrm{G})$ is determined from the following relationship:

$$
\Delta \mathrm{G}=\Delta \mathrm{H}-\mathrm{T} \Delta \mathrm{S}
$$

In eqn. $4, \mathrm{~K}$ is analogous to the binding constants $\mathrm{K}_{\mathrm{b}}$ at the corresponding temperature and $\mathrm{R}$ is the gas constant. The temperatures used were $298,302,306$ and $310 \mathrm{~K}$, respectively. The enthalpy change $(\Delta \mathrm{H})$ and entropy change $(\Delta \mathrm{S})$ were calculated from the slope and ordinate of the van't Hoff relationship. According to the binding constants of sodium fluorescein to human serum albumin obtained at four temperatures above, the thermodynamic parameters were obtained from the linear van't Hoff plot (Fig. 6) As shown in Table-1, the negative values of $(\Delta \mathrm{G})$ meant that the binding process is spontaneous. The negative $\Delta \mathrm{H}$ and positive $\Delta \mathrm{S}$ values indicated that the electrostatic interactions play a dominant role in the interactions between sodium fluorescein and human serum albumin ${ }^{26}$.

\section{Conformation investigation}

Synchronous fluorescence spectroscopy studies: The synchronous fluorescence spectra can give information about the molecular environment in the vicinity of the chromosphere molecules. When the wavelength interval $(\Delta \lambda)$ between excitation wavelength and emission wavelength is 15 and $60 \mathrm{~nm}$, the synchronous fluorescence spectra offer the characteristics of tyrosine and the tryptophan residues of human serum albumin $^{27}$. Thus, the synchronous fluorescence spectra of $\Delta \lambda$ $=15$ and $60 \mathrm{~nm}$ were studied and shown in Fig. 7. Under the both conditions, sodium fluorescein could quench the fluorescence

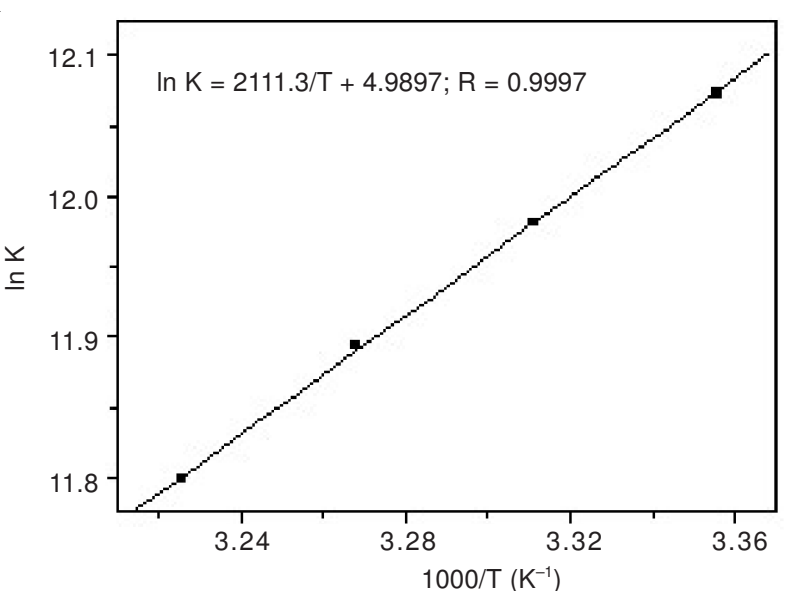

Fig. 6. Van't Hoff plot for the interaction of sodium fluorescein and human serum albumin, $\mathrm{pH} 7.4$
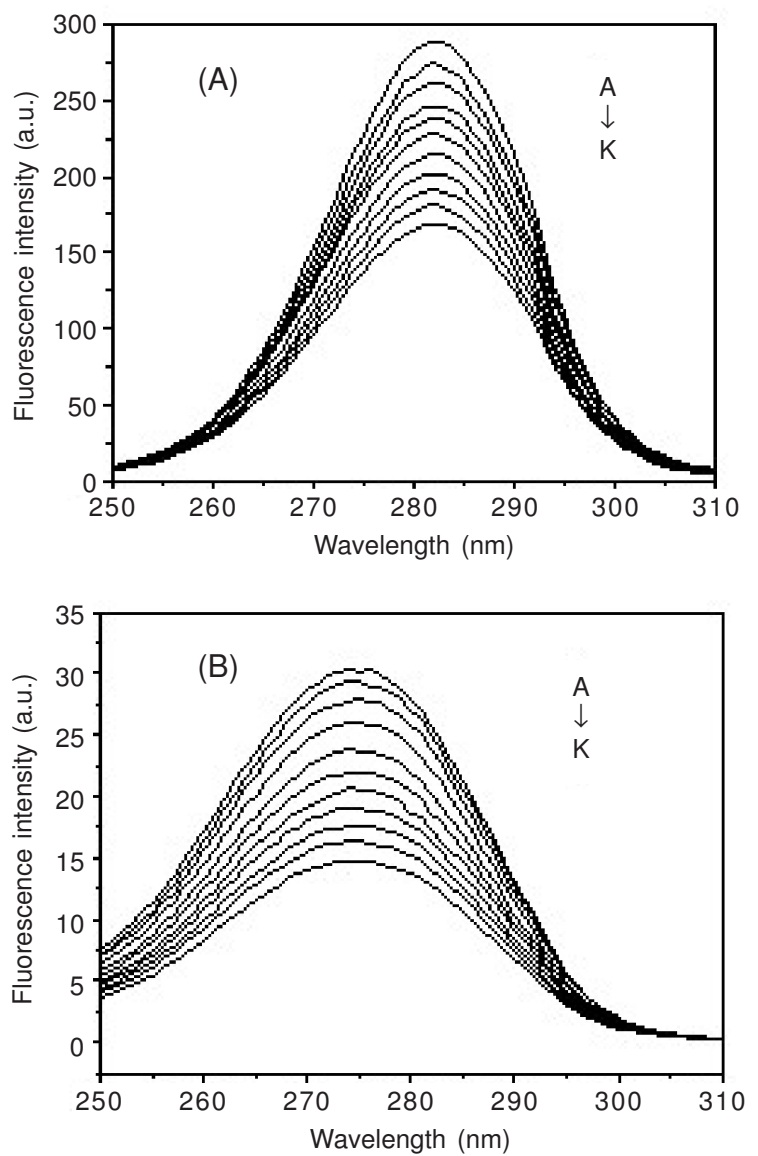

Fig. 7. Synchronous fluorescence spectra of human serum albumin: (a) $\Delta \lambda=60 \mathrm{~nm}$; (b) $\Delta \lambda=15 \mathrm{~nm}$; the concentrations of human serum albumin and sodium fluorescein were same in the Fig. 2

of human serum albumin significantly, indicating that sodium fluorescein could bind to tyrosine and tryptophan residues simultaneously. It can be seen from Fig. 7A that the maximum emission wavelength of tryptophan residues has a slight red shift (from 281 to $283 \mathrm{~nm}$ ). However, no obvious wavelength shift of tyrosine residues was observed in Fig. 7B, which suggested that a more hydrophilic environment of tryptophan residues, yet the micro-environment of the tyrosine residue had no remarkable change ${ }^{28}$. Moreover, the fluorescence intensity decreased regularly with the addition of sodium fluorescein 
in both figures, which further demonstrated the occurrence of fluorescence quenching during the binding process.

Circular dichroism spectroscopy: The CD is a sensitive technique to monitor the conformational changes in the protein upon interaction with the ligand. To further investigate whether any conformational changes of human serum albumin molecules occurred in the binding reaction, $\mathrm{CD}$ experiments of human serum albumin in the absence and presence of sodium fluorescein at $\mathrm{pH} 7.4$ and room temperature were carried out. The CD spectra of human serum albumin exhibited two negative bands in the UV region at 208 and $218 \mathrm{~nm}$, characteristic of an $\alpha$-helical structure of protein ${ }^{29}$ (Fig. 8 curve A). The $C D$ results were expressed in terms of mean residue ellipticity (MRE) in $\operatorname{deg~} \mathrm{cm}^{2} \mathrm{~d} \mathrm{~mol}^{-1}$ according to the following equation $^{30}$.

$$
\text { MRE }=\frac{\text { Observed CD }(\text { mdeg })}{C_{\mathrm{P}} \mathrm{nl} \times 10}
$$

where $C_{P}$ is the molar concentration of the protein, $n$ is the number of amino acid residues and $l$ is the path length. The $\alpha$-helical contents of free and combined human serum albumin were calculated from MRE values at $208 \mathrm{~nm}$ using the equation:

$$
\alpha-\operatorname{Helix}(\%)=\frac{-\mathrm{MRE}_{208}-4000}{33,000-4000} \times 100
$$

where $\mathrm{MRE}_{208}$ is the observed MRE value at $208 \mathrm{~nm}, 4000$ is the MRE of the $\beta$-form and random coil conformation cross at $208 \mathrm{~nm}$ and 33,000 is the MRE value of a pure $\alpha$-helix at $208 \mathrm{~nm}$. From the above equation, the quantitative analysis results of the $\alpha$-helix in the secondary structure of human serum albumin were obtained. The $\alpha$-helix content differed from that of $46.15 \%$ in free human serum albumin to $38.79 \%$ when the molar ratio of SF-HSA reached 10:1, which was indicative of the loss of $\alpha$-helix upon the interaction. And the loss of the $\alpha$-helix indicated that sodium fluorescein bound with the amino acid residues of the main polypeptide chain of protein and destroyed their hydrogen bonding networks ${ }^{31}$. The CD spectra of human serum albumin in the presence and absence of sodium fluorescein were observed to be similar in shape, which meant that the structure of human serum albumin was also predominantly of $\alpha$-helix. From the above analysis, it is concluded that the binding of SF-HSA induced some secondary-structure changes in human serum albumin.

Three-dimensional fluorescence spectroscopy analysis: Three-dimensional fluorescence spectroscopy can comprehensively exhibit the information of conformational change of protein. The maximum emission wavelength and fluorescence intensity of the residues have a close relation to the polarity of their micro-environment. The three-dimensional fluorescence

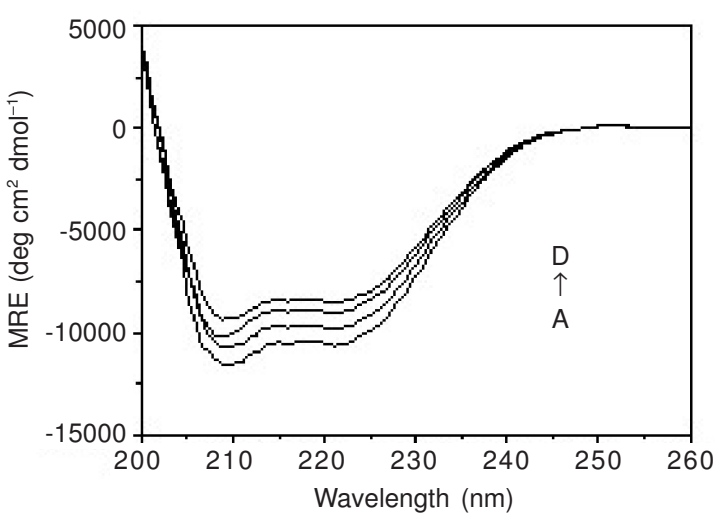

Fig. 8. CD spectra of SF-HSA system obtained in Tris-buffer at room temperature. $\mathrm{c}(\mathrm{HSA})=5.0 \mu \mathrm{M} ; \mathrm{c}(\mathrm{SF}) /(\mu \mathrm{M}), \mathrm{A}-\mathrm{D}: 0,15.0,25.0$, 50.0 , respectively

spectra of human serum albumin and SF-HSA complex are shown in Fig. 9 and the corresponding characteristic parameters are presented in Table-2. As shown in Fig. 9, peak $\alpha$ is the Rayleigh scattering peak $\left(\lambda_{\text {ex }}=\lambda_{\text {em }}\right)^{19}$ and the fluorescence intensity of peak $\alpha$ increased with the addition of sodium fluorescein. The reasonable explanation is that a SF-HSA complex came into being after the addition of sodium fluorescein, making the diameter of the macromolecule increased, which in turn resulted in the scattering effect enhanced ${ }^{32}$. As referred to peak $1\left(\lambda_{\text {ex }}=280 \mathrm{~nm}, \lambda_{\text {em }}=340 \mathrm{~nm}\right)$, we presume that it mainly reveals the spectral characters of tyrosine and tryptophan residues and the fluorescence of phenylalanine residue can be negligible ${ }^{33}$. The results in Fig. 9B and Table-2 show that the fluorescence intensity of peak 1 decreased by $36.63 \%$, which indicated that the polarity of both residues increases and more amino residues of human serum albumin were exposed from the hydrophobic pocket. Tryptophan emission dominates both serum albumins fluorescence spectra around $340 \mathrm{~nm}$ when excited at $280 \mathrm{~nm}$ and lower polarity meant that the binding position between sodium fluorescein and human serum albumin located within this hydrophobic pocket and near by the Trp-214. And the addition of sodium fluorescein changed the polarity of this hydrophilic micro-environment and the conformation of human serum albumin.

Besides peak 1, there is another new strong fluorescence peak $2\left(\lambda_{\text {ex }}=225.0 \mathrm{~nm}, \lambda_{\text {em }}=340.0 \mathrm{~nm}\right)$. According to literature $^{34}$, peak 2 might mainly exhibit the fluorescence spectra behaviour of polypeptide backbone structures of $\pi-\pi^{*}$ of human serum albumin's characteristic polypeptide backbone structure $\mathrm{C}=\mathrm{O}$. Upon addition of sodium fluorescein, the fluorescence intensity of peak 2 decreased by $45.49 \%$ after the addition of sodium fluorescein, which demonstrated that the peptide strands structure of protein was changed and this was

TABLE-2

THREE-DIMENSIONAL FLUORESCENCE SPECTRUM CHARACTERISTICS PARAMETERS OF HSA AND SF-HSA SYSTEM

\begin{tabular}{clccc}
\hline Systems & \multicolumn{1}{c}{ Parameters } & Peak 1 & Peak 2 & Rayleigh scattering peaks \\
\hline \multirow{3}{*}{ HSA } & Peak position $\left(\lambda_{\text {ex }} / \lambda_{\text {em }}\right)(\mathrm{nm} / \mathrm{nm})$ & $280.0 / 340.0$ & $225.0 / 340.0$ & $275 / 275 \rightarrow 320 / 320$ \\
& Fluorescence intensity & 300.9 & 184.4 & $185.1 \rightarrow 187.6$ \\
& Stokes shift $\Delta \lambda(\mathrm{nm})$ & 60.0 & 115.0 & 0 \\
\hline \multirow{3}{*}{ SF-HSA } & Peak position $\left(\lambda_{\text {ex }} / \lambda_{\text {em }}\right)(\mathrm{nm} / \mathrm{nm})$ & $280.0 / 340.0$ & $225.0 / 340.0$ & $275 / 275 \rightarrow 320 / 320$ \\
& Fluorescence intensity & 189.6 & 106.5 & $245.7 \rightarrow 235.9$ \\
& Stokes shift $\Delta \lambda(\mathrm{nm})$ & 60.0 & 115.0 & 0 \\
\hline
\end{tabular}



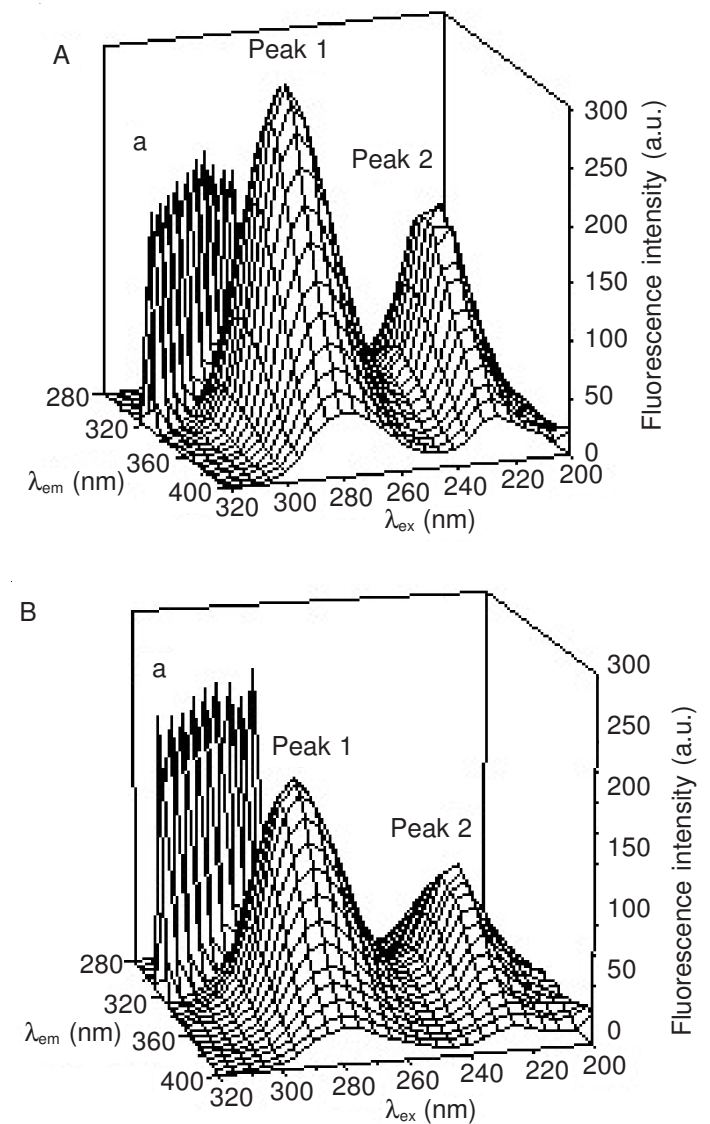

Fig. 9. Three-dimensional fluorescence spectra of human serum albumin (A) and the SF-HSA system (B). (A): $\mathrm{c}(\mathrm{HSA})=5.0 \mu \mathrm{M}, \mathrm{c}(\mathrm{SF})=0$; (B): $c(H S A)=5.0 \mu \mathrm{M}, \mathrm{c}(\mathrm{SF})=2.0 \mu \mathrm{M}$

in accordance of the decrease of $\alpha$-helix content in the CD spectra. The above phenomena and the analysis of the fluorescence characteristic of the two peaks in combination with the synchronous fluorescence and circular dichroism spectra results revealed that the interactions between sodium fluorescein and human serum albumin induced the slight unfolding of the polypeptides of protein, which resulted in a conformational change of the protein that increased the exposure of some hydrophobic regions which were previously buried ${ }^{35}$.

\section{Conclusion}

In this paper, the interaction between sodium fluorescein and human serum albumin was studied by fluorescence spectroscopy combined with UV-visible and CD spectroscopy under simulative physiological conditions. The fluorescence experiment results revealed that the fluorescence quenching of human serum albumin was resulted mainly from static mechanism and the effective quenching constants $\left(\mathrm{K}_{\mathrm{a}}\right)$ and number of binding sites $(\mathrm{n})$ were obtained. The enthalpy change $(\Delta \mathrm{H})$ and entropy change $(\Delta S)$ for the reaction were calculated to be $-17.55 \mathrm{~kJ}$ $\mathrm{mol}^{-1}$ and $41.48 \mathrm{~J} \mathrm{~mol}^{-1} \mathrm{~K}^{-1}$, indicating that electrostatic interactions was the dominant intermolecular force in stabilizing the complex. In the conformational investigation, the spectroscopic results (synchronous fluorescence spectra, CD and three-dimensional fluorescence spectra) revealed that the microenvironment's polarity of the amino residues and the conformation of human serum albumin molecular were changed in the presence of sodium fluorescein. This work is expected to provide guidelines into understanding the transportation and distribution of sodium fluorescein in vitro and illustrating the binding mechanism of contrast agent at a molecular level.

\section{ACKNOWLEDGEMENTS}

Program of Xi'an Industrial Application Technology Research and Development (CXY09023).

\section{REFERENCES}

1. Z.D. Qi, B. Zhou, X. Qi, S. Chuan, Y. Liu and J. Dai, J. Photochem. Photobiol. A, 193, 81 (2008).

2. J.B. Xiao, J.W. Chen, H. Cao, F.L. Ren, C.S. Yang, Y. Chen and M. Xu, J. Photochem. Photobiol. A, 191, 222 (2007).

3. I. Petitpas, T. Grune, A.A. Bhattacharya and S. Curry, J. Mol. Biol., 314, 955 (2001).

4. R.K. Nanda, N. Sarkar and R. Banerjee, J. Photochem. Photobiol. A, 192, 152 (2007).

5. R. Kiesslich, L. Gossner, M. Goetz, A. Dahlman, M. Vieth, M. Stolte, A. Hoffman, M. Jung, B. Nafe, P.R. Galle and M.F. Neurath, Clin. Gastroenterol. Hepatol., 4, 979 (2006).

6. A. Hoffman, M. Goetz, M. Vieth, P.R. Galle, M.F. Neurath and R. Kiesslich, Endoscopy., 38, 1275 (2006).

7. M. Noppen, G. Stratakos, S. Verbanck, J. D'Haese, M. Meysman and W. Vincken, Am. J. Respir. Crit. Care Med., 170, 680 (2004).

8. D.I. Gheonea, A. Saftoiu, T. Ciurea, C. Popescu, C.V. Georgescu and A. Malos, Gastrointestin. Liver. Dis., 19, 207 (2010).

9. C. Gheorghe, M. Dumbrava, R. Iacob, L. Gheorghe, V. Herlea and M. Ionescu, Arch. Union. Med Balkan., 42, 69 (2007).

10. J.A. Evans and N.S. Nishioka, Curr. Opin. Gastroenterol, 21, 578 (2005).

11. R. Kiesslich, M. Goetz, J. Burg, M. Stolte, E. Siegel, M.J. Maeurer, S. Thomas, D. Strand, P.R. Galle and M.F. Neurath, Gastroenterology, 128, A73 (2005).

12. Y.Z. Zhang, J. Dai, X.P. Zhang, X. Yang and Y. Liu, J. Mol. Struct., 888, 152 (2008).

13. S.M.T. Shaikh, J. Seetharamappa, S. Ashoka and P.B. Kandagal, Dyes Pigm., 73, 211 (2007).

14. Y.Y. Yue, X.G. Chen, J. Qin and X.J. Yao, Dyes Pigm., 79, 176 (2008).

15. Y.Z. Zhang, B. Zhou, X.P. Zhang, P. Huang, C.H. Li and Y. Liu, J. Hazard. Mater., 163, 1345 (2009).

16. X.Z. Feng, Z. Lin, L.J. Yang, C. Wang and C.L. Bai, Talanta, 47, 1223 (1998).

17. N. Barbero, E. Barni, C. Barolo, P. Quagliotto, G. Viscardi, L. Napione, S. Pavan and F. Bussolino, Dyes Pigments, 80, 308 (2009).

18. Y.J. Hu, Y. Liu, R.M. Zhao, J.X. Dong and S.S. Qu, J. Photochem. Photobiol. A Chem., 179, 324 (2006).

19. H.X. Zhang, X. Huang, P. Mei, K.H. Li and C.N. Yan, J. Fluoresc., 16, 287 (2006).

20. E.L. Gelamo, C.H.T.P. Silva, H. Imasato and M. Tabak, Biochim. Biophys. Acta, 1594, 84 (2002).

21. W.M. Vaughan and G. Weber, Biochemistry, 9, 464 (1970).

22. J.R. Lakowicz and G. Weber, Biochemistry, 12, 4161 (1973).

23. S.N. Sharma, H. Sharma, G. Singh and S.M. Shivaprasad, Mater. Chem. Phys., 110, 471 (2008).

24. C. Wang, Q.H. Wu, Z. Wang and J. Zhao, Anal. Sci., 22, 435 (2006).

25. H. Gao, L.D. Lei, J.Q. Liu, Q. Kong, X.G. Chen and Z.D. Hu, J. Photochem. Photobiol. A, 167, 213 (2004).

26. P.D. Ross and S. Subramanian, Biochemistry, 20, 3096 (1981).

27. J.N. Miller, Proc. Anal. Div. Chem. Soc., 16, 203 (1979).

28. G.W. Zhang, Q.M. Que, J.H. Pan and J.B. Guo, J. Mol. Struct., 881, 132 (2008).

29. P.B. Kandagal, S.M.T. Shaikh, D.H. Manjunatha, J. Seetharamappa and B.S. Nagaralli, J. Photochem. Photobiol. A, 189, 121 (2007).

30. B.P. Kamat and J. Seetharamappa, J. Pharm. Biomed. Anal., 35, 655 (2004).

31. F.L. Cui, J. Fan, J.P. Li and Z.D. Hu, Bioorg. Med. Chem., 12, 151 (2004).

32. Y.Z. Zhang, B. Zhou, Y.X. Liu, C.X. Zhou, X.L. Ding and Y. Liu, J. Fluoresc., 18, 109 (2008).

33. A. Sulkowska, J. Mol. Struct., 614, 227 (2002).

34. Q. Xiao, S. Huang, Y. Liu, F.F. Tian and J.C. Zhu, J. Fluoresc., 19, 317 (2009).

35. J.N. Tian, J.Q. Liu, Z.D. Hu and X.G. Chen, Bioorg. Med. Chem., 13, 4124 (2005). 